\title{
AVALIAÇÃO DA SUBSTITUIÇÃO PARCIAL DE FARINHA DA SEMENTE DA MAMA-CADELA NA ELABORAÇÃO DE PÃO DE MEL
}

\author{
Vânia Maria Alves; Danilo José Machado De Abreu²; Ingrid Alves De Moraes; Talysson \\ Rodrigues Castro Lessa ${ }^{1}$; Natalia Ferreira Da Silva ${ }^{1}$; Katiúcia Alves Amorim² ${ }^{2}$ Edson Pablo Da \\ Silva ${ }^{3}$; Clarissa Damiani³ ${ }^{3}$ vanialvees@gmail.com) \\ ${ }^{1}$ Graduando em Engenharia de Alimentos, Universidade Federal de Goiás, Goiânia-Go, Brasil. \\ ${ }^{2}$ Programa de Pós-graduação em Ciência e Tecnologia de Alimentos, Universidade Federal de Goiás, Goiânia-Go, \\ Brasil. \\ ${ }^{3}$ Departamento de Engenharia de Alimentos, Universidade Federal de Goiás, Goiânia-Go, Brasil.
}

O cerrado é considerado uma das regiões de maior biodiversidade do planeta, dentre as várias espécies encontradas nesse bioma, destaca-se a mama-cadela (Brosimium gaudichaudii Trecúl). Com a mudança de habito e a necessidade de consumir produtos com maior teor nutricional, o processamento de frutos e seus resíduos vem demonstrando uma alternativa para a inserção de produtos integrais, principalmente como farinhas, geléias. Logo o objetivo desde trabalho foi à aplicação de farinha de semente de mamacadela (Brosimum gaudichaudii Trecúl) em substituição parcial de farinha de trigo no pão de mel, bem como avaliar as características físicas. Os pães de mel foram elaborados na Planta Piloto de Panificação, do Departamento de Engenharia de Alimentos, da Escola de Agronomia, da Universidade Federal de Goiás, sendo duas formulações com diferentes concentrações de farinha de semente de mama-cadela (15\% e 25\%) sem a aplicação de cobertura de chocolate, partindo de uma formulação padrão de pão de mel. Foram realizadas analise de cor, na superfície e no miolo, textura, avaliando a dureza, a adesividade, a elasticidade, a coesividade, a gomosidade, a mastigabilidade e a resiliência, e microscopia eletrônica de varredura (MEV), para a farinha da semente de mama-cadela. Dessa forma, quanto aos parâmetros de cor, o parâmetro $L^{*}$ não se diferenciou nos tratamentos, para $a^{*}$ na superfície percebe-se que não houve diferença estatística entre os três tratamentos e houve aumento da cor no miolo apenas na concentração de $15 \%$. Para $b^{*}$, houve um aumento dos valores apenas na concentração de $15 \%$, em especifico no miolo. Para a textura, a adição de farinha de mama cadela mostrou-se uma melhora significativa em todos os quesitos quando comparado ao pão de mel padrão, observando decréscimo de parâmetros como dureza, mastigabilidade, e cisalhamento, não havendo diferença estatística entre as diferentes concentrações farinha. Quanto a MEV, temos que a farinha de semente de mama-cadela apresenta uma estrutura mais definida, sendo os seus grânulos mais achatados e menores que a farinha de trigo influenciando na absorção de líquidos como o leite e água. Portanto, a farinha da semente da mama-cadela pode ser considerada um ingrediente alternativo para a substituição parcial a farinhas trigo, levando em consideração as características físicas do produto final. 